\title{
Morphology and oxygen incorporation effect on antimicrobial activity of silver thin films
}

\author{
Rita Rebelo $^{\mathrm{a}, \mathrm{b}, \mathrm{c}, *}$, N.K. Manninen ${ }^{\mathrm{b}, \mathrm{d}}$, Luísa Fialho ${ }^{\mathrm{b}}$, Mariana Henriques ${ }^{\mathrm{c}}$, \\ Sandra Carvalho ${ }^{\mathrm{b}, \mathrm{d}}$ \\ a 2C2T, University of Minho, Campus de Azurém, 4800-058 Guimarães, Portugal \\ b GRF-CFUM, University of Minho, Campus de Azurém, 4800-058 Guimarães, Portugal \\ ' CEB, Center for Biological Engineering, LIBRO-Laboratório de Biofilmes Rosário Oliveira, University of Minho, Campus de Gualtar, 4710-335 Braga, \\ Portugal \\ d SEG-CEMUC, University of Coimbra, 3030-788 Coimbra, Portugal
}

\section{A R T I C L E I N F O}

\section{Article history:}

Received 15 July 2015

Received in revised form 12 February 2016

Accepted 15 February 2016

Available online 18 February 2016

\section{Keywords:}

Silver nanoparticles

Silver oxide thin films

Sputtering

Microstructure

Halo tests

\begin{abstract}
A B S T R A C T
$\mathrm{Ag}$ and $\mathrm{Ag}_{x} \mathrm{O}$ thin films were deposited by non-reactive and reactive pulsed DC magnetron sputtering, respectively, with the final propose of functionalizing the SS316L substrate with antibacterial properties. The coatings were characterized chemically, physically and structurally. The coatings nanostructure was assessed by X-ray diffraction (XRD) and X-ray photoelectron spectroscopy (XPS), while the coatings morphology was determined by scanning electron microscopy (SEM). The XRD and XPS analyses suggested that $\mathrm{Ag}$ thin film is composed by metallic $\mathrm{Ag}$, which crystallizes in fcc-Ag phase, while the $\mathrm{Ag}_{x} \mathrm{O}$ thin film showed both metallic $\mathrm{Ag}$ and $\mathrm{Ag}-\mathrm{O}$ bonds, which crystalize in fcc-Ag and silver oxide phases. The SEM results revealed that $\mathrm{Ag}$ thin film formed a continuous layer, while $\mathrm{Ag}_{x} \mathrm{O}$ layer was composed of islands with hundreds of nanometers surrounded by small nanoparticles with tens of nanometers. The surface wettability and surface tension parameters were determined by contact angle measurements, being found that $\mathrm{Ag}$ and $\mathrm{Ag}_{x} \mathrm{O}$ surfaces showed very similar behavior, with all the surfaces showing a hydrophobic character.

In order to verify the antibacterial behavior of the coatings, halo inhibition zone tests were realized for Staphylococcus epidermidis and Staphylococcus aureus. Ag coatings did not show antibacterial behavior, contrarily to $\mathrm{Ag}_{x} \mathrm{O}$ coating, which presented antibacterial properties against the studied bacteria. The presence of silver oxide phase along with the development of different morphology was pointed as the main factors in the origin of the antibacterial effect found in $\mathrm{Ag}_{x} \mathrm{O}$ thin film. The present study demonstrated that $\mathrm{Ag}_{x} \mathrm{O}$ coating presented antibacterial behavior and its application in cardiovascular stents is promising.
\end{abstract}

(C) 2016 Elsevier B.V. All rights reserved.

\section{Introduction}

Cardiovascular diseases (CVD) are the leading cause of death worldwide. In Europe, CVD are responsible for $40 \%$ of deaths and thereis an estimated annual cost of 196 billion euros spent between health care, informal care and loss of productivity related to these diseases [1]. In this context, cardiovascular stents assume a great value in the treatment of vascular obstructions. These devices are inserted in blood vessels to keep them open, using mechanical pressure until blood circulation normalizes [2]. Despite the great

\footnotetext{
* Corresponding author at: 2C2T, University of Minho, Campus de Azurém, 4800058 Guimarães, Portugal.

E-mail address: ritarebelo@det.uminho.pt (R. Rebelo).
}

innovations in the development of new stents with improved lifetime, namely the use of fibrous materials instead of metal, in order to avoid corrosion, stents, independently of the material, present some disadvantages like bacterial colonization, which leads to the occurrence of infections. Usually, these infections result in prolonged hospitalization with consequent high costs and, in extreme cases, death of the patient (especially immunocompromised ones) [3]. Infection of medical devices can arise due to several reasons and from different sources; some of the most common sources of infection are: contaminated device surfaces, hands of medical staff and patients own skin or mucus membrane, among others. Many of these risk factors can be easily avoided, but, infections are impossible to evade completely [4]. One of the most common bacteria in nosocomial sepsis is Staphylococcus epidermidis, which is a 
gram-positive, coagulase-negative Staphylococcus that is a part of our normal flora and colonizes the skin and mucous membranes of the human body [5]. Another bacterium associated with coronary diseases is Staphylococcus aureus, which is a gram-positive bacterium that can be found in the human respiratory tract and skin $[6,7]$. Thus, in order to prolong the stent lifetime and patientís safety the development of new stent materials with antibacterial properties is of great importance.

In the past years, silver has been studied as an antimicrobial agent [8-10]. The antimicrobial effect provided by silver depends on the amount of silver and the rate of $\mathrm{Ag}^{+}$released along time. Silver can exist in diverse forms: as metal, as a compound or as a free dissolved ion. The exact mechanism of the antimicrobial action of silver is not fully understood yet, still several theories have been pointed to explain its bactericidal effect, namely: (i) release of $\mathrm{Ag}^{+}$ ions; (ii) direct interaction between $\mathrm{Ag}$ nanoparticles and bacteria and (iii) formation of reactive oxygen species; among them the $\mathrm{Ag}^{+}$ are claimed to be the most effective bactericidal agent $[11,12,9]$. In respect to silver ions, their antimicrobial activity is attributed to the structural and morphological changes induced in bacteria. Silver ions can penetrate inside bacterial cells, inhibiting the DNA replication and, consequently, causing cell lysis. Moreover, silver ions have a far lower propensity than classic antibiotics to induce high-level, single-step resistance mutations $[9,13]$.

The antibacterial efficiency of bulk $\mathrm{Ag}$ and $\mathrm{Ag}$ thin films is quite poor due to the high stability of Ag, which turns its ionization and solubility in water very low. In fact, any perfectly formed metallic surface in contact with an electrolyte will stabilize quickly; thus if a continuous release of $\mathrm{Ag}^{+}$ions is required, a driving force must exist to provide silver ionization. In order to achieve a continuous ion release researchers have attempted many novel activation processes, such as: thermal, mechanical, chemical and electrical stimulation [14-17], still, in a practical point of view the application of these external driving forces are quite complex. Sant et al. [12] claimed that the presence of heterogeneities in Ag based coatings enable to develop bioactive films. In fact, those authors found that the presence of fine grain size, incorporation of oxygen species and presence of lattice defects allowed to improve the $\mathrm{Ag}^{+}$dissolution rate, which is attributed to the high energy associated with these structural defects. Another adopted approach is the incorporation of $\mathrm{Ag}$ nanoparticles in different matrix coatings or polymers, which are claimed to present an effective bactericidal effect, due to their higher reactivity, promoted by the high surface to volume ratio [12].

Thus, the main objective of this work is the modification of stainless steel (SS316L) surfaces (the most common material used in cardiovascular stents) with silver and silver oxide thin films deposited by pulsed DC reactive magnetron sputtering, for cardiovascular stents application, with the aim of providing antibacterial properties. The antibacterial activity was determined by halo inhibition zone tests against $S$. epidermidis and $S$. aureus. The coatings structure, morphology and surface characteristics were evaluated in order to understand the influence of these parameters on the biological response.

\section{Experimental details}

\subsection{Sample preparation}

$\mathrm{Ag}$ and $\mathrm{Ag}_{x} \mathrm{O}$ coatings were deposited onto 316L stainless steel $(20 \times 20 \mathrm{~mm})$ and silicon substrates $(10 \times 10 \mathrm{~mm})$ by reactive pulsed DC magnetron sputtering. Stainless steel 316L substrates were used in all characterization techniques that evaluate the functional properties, while silicon substrates were used in characterization techniques that evaluate the coatingís morphology and structure. Thus, silicon substrates were used in SEM analysis, once these substrates are easily cut, while in XRD analysis, silicon avoids the appearance of substrate's peaks. In XPS, since silicon's surface is smoother than stainless steel 316L, the analysis is more reliable. Before deposition the substrates were ultrasonically cleaned with distillate water, ethanol and acetone during $10 \mathrm{~min}$ in each solution. In order to minimize the contamination and remove impurities, before each deposition, the silver target and the substrates were cleaned by an argon plasma etching process during $5 \mathrm{~min}$. The etching process was performed in an argon atmosphere ( $\mathrm{Ar}$ flow of $80 \mathrm{sccm}$ ) and by applying a pulsed DC power supply with a current density of $400 \mathrm{~mA}$ and a reverse time and frequency of $1536 \mathrm{~ns}$ and $200 \mathrm{kHz}$ to the substrate holder. Simultaneously, the Ag target was connected to a DC power supply, and a current density of $0.5 \mathrm{~mA} / \mathrm{cm}^{2}$ was applied. The silver based coatings were deposited from an Ag target (purity of 99.99\%) with $200 \times 100 \mathrm{~mm}^{2}$. During deposition, the sputtering atmosphere consisted in a constant argon flow ( $60 \mathrm{sccm})$ for both coatings and for oxide coating oxygen was introduced with a constant flow of $15 \mathrm{sccm}$. Samples were placed in a substrate holder that rotated at a constant velocity of $7 \mathrm{rpm}, 70 \mathrm{~mm}$ away from the target. The current density applied from a pulsed DC power supply to the Ag target was $2.5 \mathrm{~mA} / \mathrm{cm}^{2}$ and $1 \mathrm{~mA} / \mathrm{cm}^{2}$, for the deposition of $\mathrm{Ag}$ and $\mathrm{Ag}_{\mathrm{x}} \mathrm{O}$ coatings, respectively. The reverse time and frequency were kept at $1536 \mathrm{~ns}$ and $200 \mathrm{kHz}$, respectively.

\subsection{Surface characterization}

XPS analysis was performed in order to obtain information about the coatings binding state. The analysis was performed on silicon samples coated with $\mathrm{Ag}$ and $\mathrm{Ag}_{x} \mathrm{O}$ in a Kratos AXIS Ultra HSA equipment, with VISION software for data acquisition and CASAXPS software for data analysis. The analysis was carried out with a monochromatic Al K $\alpha$ X-ray source $(1486.7 \mathrm{eV})$, operating at $15 \mathrm{kV}$ $(90 \mathrm{~W})$, in FAT mode (Fixed Analyser Transmission), with a pass energy of $40 \mathrm{eV}$ and a pass of $0.1 \mathrm{eV}$ for regions ROI and $80 \mathrm{eV}$ of pass energy and $1.0 \mathrm{eV}$ of step for survey. Data acquisition was performed with a pressure lower than $1 \times 10^{-6} \mathrm{~Pa}$, and a charge neutralization system was used. The effect of the electric charge was corrected by the reference of the carbon peak $(285 \mathrm{eV})$. The samples were sputter-cleaned in situ using a broad $2 \mathrm{keV} \mathrm{Ar}+$ beam for $5 \mathrm{~min}$.

The morphology of $\mathrm{Ag}$ and $\mathrm{Ag}_{x} \mathrm{O}$ coatings deposited in SS316L and the thickness of coatings deposited on silicon substrates were evaluated by scanning electron microscopy (SEM) analysis in an EDAXNova nano-SEM200 equipment, being analyzed 3 different regions and presented a representative micrograph.

$\mathrm{X}$-ray diffraction (XRD) analysis was carried out in order to understand the structure and phase distribution of the coatings, in a PANalytical X'Pert PRO MPD system using CuK $\alpha$ radiation $(45 \mathrm{kV}$ and $40 \mathrm{~mA}$ ) with a parallel beam configuration. The analysis was performed in grazing incidence mode with an angle of incidence of $5^{\circ}$. The X-rays reach the entire sample area, thus only one sample was analyzed, which is the common procedure in this technique. The grain size was determined by Scherrer formula using the (1111) peak in case of Ag thin film. The XRD peak was fitted with pseudovoigt function, which allowed us to calculate either the full-width

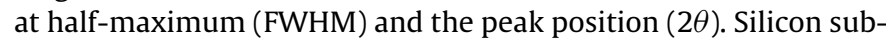
strates were used for XRD analysis.

The coatings hydrophobicity was evaluated through contact angle measurements, using the van Oss approach in coatings deposited onto SS316L substrate. For the contact angle analysis, 8 measurements were made, with three different liquids: water, formamide and $\alpha$-bromonaphtalene, with different values of surface free energy, $Y_{1}^{\text {Tot }}$; apolar Lifshitz-van der Waals surface free energy component, $Y_{1}^{\text {lw; }}$; electron acceptor surface free energy compo- 


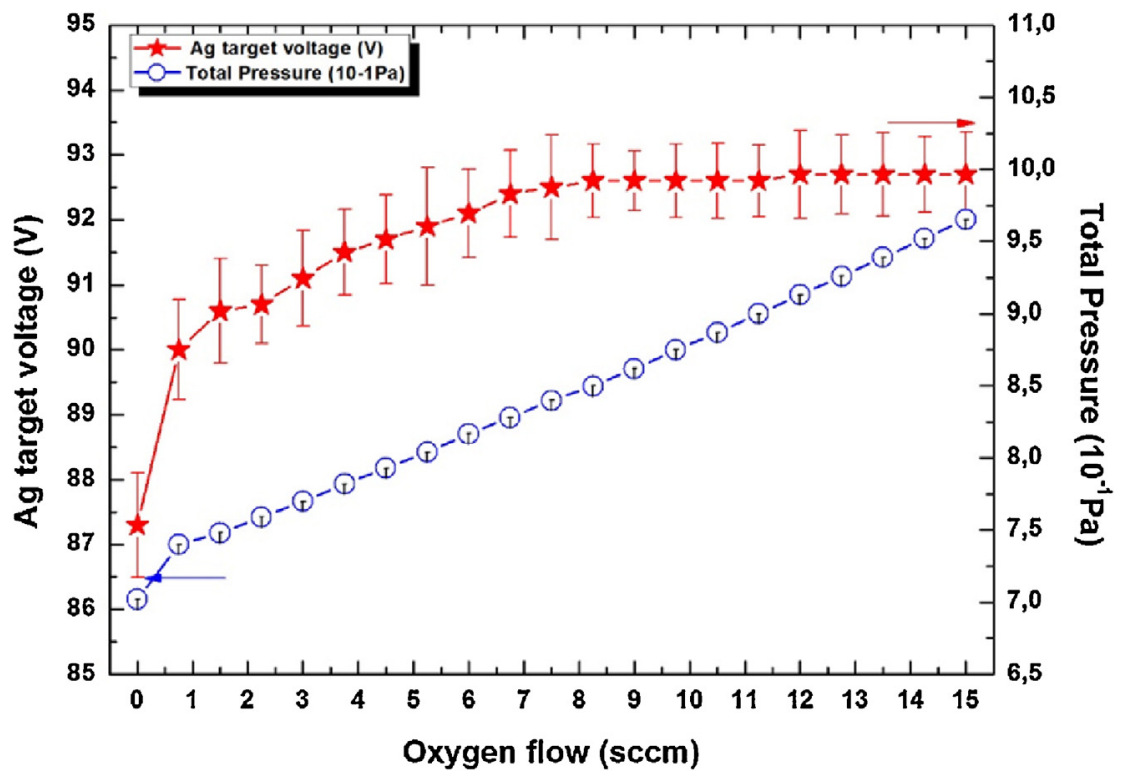

Fig. 1. Variation of Ag target voltage and total pressure in deposition chamber for different $\mathrm{O}_{2}$ flows (at a constant $J_{\mathrm{Ag}}$ of $\left.1 \mathrm{~mA} / \mathrm{cm}^{2}\right)$.

Table 1

Surface energy components for tested liquids.

\begin{tabular}{lllcc}
\hline & $Y_{1}^{\text {Tot }}$ & $Y_{1}^{\text {lw }}$ & $Y_{1}^{+}$ & $Y_{1^{-}}$ \\
\hline Water & 72.8 & 21.8 & 25.5 & 25.5 \\
Formamide & 44.4 & 44.4 & 0 & 0 \\
$\alpha$-Bromonaphtalene & 58 & 39 & 2.28 & 39.6 \\
\hline
\end{tabular}

nent, $Y_{1}^{+}$; and electron donor surface free energy component, $Y_{1}^{-}$ (Table 1). For statistical analysis $t$-tests were performed, using the software Statistical Package for the Social Sciences Inc. (SPSS). Tests were performed with a confidence level of $95 \%$.

\subsection{Antibacterial activity determination}

The antibacterial activity, against clinical isolated S. epidermidis (IE 186), and S. aureus (ATCC 6538) strains, was evaluated through halo inhibition zone tests, which is a qualitative measure of antibacterial activity, using the size of the growth inhibition halo around the sample. A colony of each species was taken from a fresh solid bacteria culture medium (Tryptic Soy Agar, TSA, Merck) and was added to $20 \mathrm{ml}$ of Tryptic Soy Broth (TSB, Merck). Then the resultant suspension was incubated overnight, at $37^{\circ} \mathrm{C}$ and $120 \mathrm{rpm}$. A volume of $1 \mathrm{ml}$ of $1 \times 10^{7} \mathrm{CFU} \mathrm{m}^{-1}$ cell suspension was added to $14 \mathrm{ml}$ of TSA (at $45^{\circ} \mathrm{C}$ ) and placed onto each petri plate. Then, square samples of the different coatings were placed in the plates and incubated for $24 \mathrm{~h}$ at $37^{\circ} \mathrm{C}$. All experiments were run in triplicate per sample (technical replicates), on three independent assays (biological replicates), for each bacterium.

The halo, corresponding to the zone of bacterial growth inhibition, formed around the sample was measured.

\section{Results and discussion}

\subsection{Deposition conditions}

The coating's deposition conditions are summarized in Table 2. The pure Ag coating was labeled as Ag, while the Ag coating deposited in reactive sputtering mode was labeled as $\operatorname{Ag}_{x} \mathrm{O}$. The $\mathrm{Ag}$ coating was deposited with $0 \mathrm{sccm}$ of $\mathrm{O}_{2}$, in order to obtain a pure Ag coating, while for the silver oxide coating the oxygen flow was selected in order to perform a deposition in reactive mode. Thus, the variation of $\mathrm{Ag}$ target voltage and total pressure in deposition chamber were measured in order to determine the necessary $\mathrm{O}_{2}$ flow for deposition in reactive mode (see Fig. 1). During reactive sputtering, a reactive gas was introduced to the discharge in order to deposit a compound material. For low reactive gas flows, all the gas atoms will react with the metal ejected from the target surface and no changes are observed either in the target voltage or in the reactive gas partial pressure, which corresponds to the deposition of compound materials in metallic mode. However, as the reactive gas flow is further increased, the reactive gas is not totally consumed by the growing thin film, which results in an increase in the gas partial pressure and also leads to the formation of a compound in the target surface. The variations in target surface condition are generally associated with a variation in effective secondary electron emission yield (SEEY), which for a constant current density, results in a significant variation on the target voltage [18]. The results presented in Fig. 1 suggest that both target voltage and total pressure in deposition chamber increase at a higher rate when an oxygen flow of $1 \mathrm{sccm}$ is introduced; afterwards the pressure increases linearly, while the target voltage increases up to $8 \mathrm{sccm}$ showing a constant value after this $\mathrm{O}_{2}$ flow. It should be pointed out that the variations in Ag target voltage with the incorporation of oxygen are small (varying from $87.3 \mathrm{~V}$ to $90 \mathrm{~V}$ with the introduction of $1 \mathrm{sccm}$ of $\mathrm{O}_{2}$ and up to $92.7 \mathrm{~V}$ for $15 \mathrm{sccm}$ ), which turns the identification of reactive mode more inaccurate. These small variations in Ag target surface condition were somehow expectable, since Depla et al. [19] reported previously that the presence of silver oxide in the target surface leads to an increase in the discharge voltage, still, the variation in relation to pure $\mathrm{Ag}$ is quite small, due to the low relative change of the effective emission coefficient by oxidation of Ag target. However, the variations of the target voltage combined with the observations in total chamber pressure allowed to predict that above $8 \mathrm{sccm}$ of $\mathrm{O}_{2}$ flow the deposition should be in reactive mode. In this study, the silver oxide coatings were deposited with $15 \mathrm{sccm}$ of $\mathrm{O}_{2}$, in reactive mode. The deposition rate of the thin films was calculated from the thickness (estimated by SEM) and the duration of deposition. Ag coating, deposited with 0 sccm of oxygen flow presented a higher deposition rate $(0.66 \mu \mathrm{m} / \mathrm{h})$ in relation to the $\mathrm{Ag}_{x} \mathrm{O}$ coating $(0.06 \mu \mathrm{m} / \mathrm{h})$, deposited with an oxygen flow of $15 \mathrm{sccm}$. This reduction in coatings deposition rate might be related to the lower current density applied to the Ag target combined with the 
Table 2

Coatings deposition conditions.

\begin{tabular}{|c|c|c|c|c|c|c|}
\hline Coating & Ar flow (sccm) & $\mathrm{O}_{2}$ flow $(\mathrm{sccm})$ & $J_{\mathrm{Ag}}\left(\mathrm{mA} / \mathrm{cm}^{2}\right)$ & Time (s) & Thickness ( $\mathrm{nm} \pm$ S.D.) & Deposition rate $(\mu \mathrm{m} / \mathrm{h})$ \\
\hline $\mathrm{Ag}$ & 60 & 0 & 2.5 & 300 & $55 \pm 5.0$ & 0.66 \\
\hline $\mathrm{Ag}_{x} \mathrm{O}$ & 60 & 15 & 1 & 3600 & $66 \pm 2.4$ & 0.06 \\
\hline
\end{tabular}

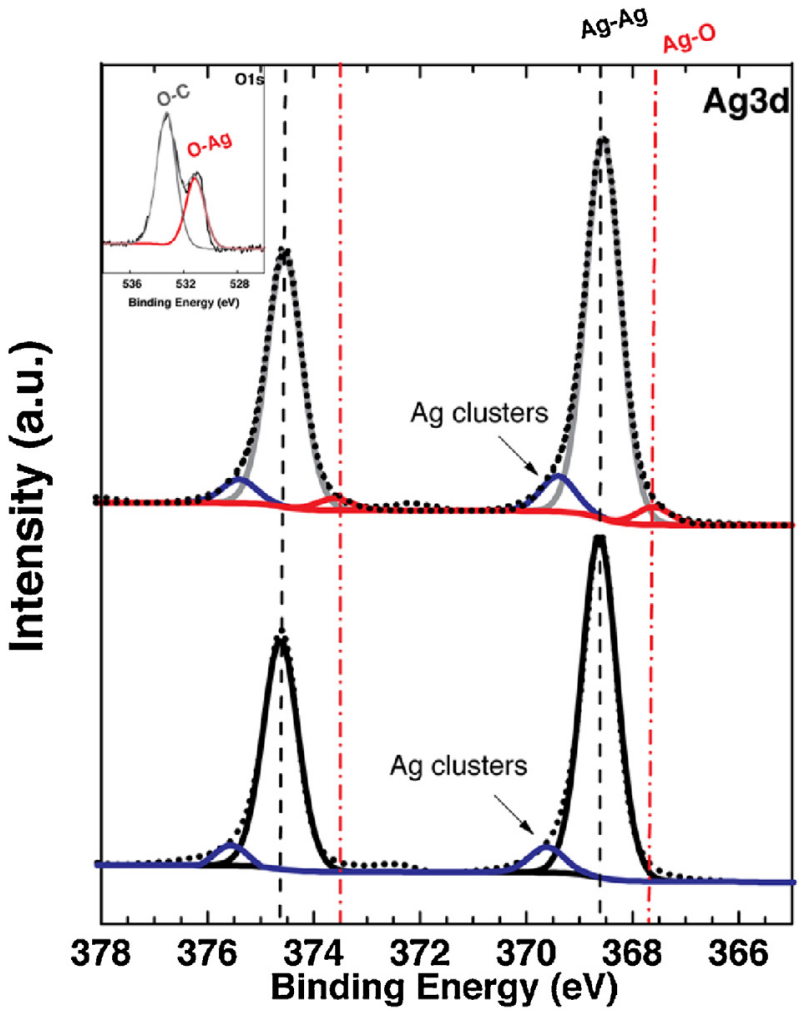

Fig. 2. XPS spectra of $\mathrm{Ag} 3 \mathrm{~d}$ core levels of $\mathrm{Ag}$ and $\mathrm{Ag}_{x} \mathrm{O}$ thin films and 01 s spectra of $\mathrm{Ag}_{x} \mathrm{O}$ thin film (inset).

presence of oxygen, which forms $\mathrm{Ag}_{\mathrm{x}} \mathrm{O}$ on targetís surface, promoting a lower sputtering yield in relation to pure $\mathrm{Ag} \mathrm{[20].}$

The deposition time was adjusted in order to obtain similar thickness for both thin films $(55 \pm 5.0 \mathrm{~nm}$ for Ag coating and $66 \pm 2.4 \mathrm{~nm}$ for $\mathrm{Ag}_{x} \mathrm{O}$ coating).

\subsection{Thin films structure and morphology}

XPS analysis was carried out in order to evaluate the coatings chemical binding state. The results are shown in Fig. 2 where the $\mathrm{Ag} 3 \mathrm{~d}$ and $\mathrm{O} 1 \mathrm{~s}$ (inset) spectra of $\mathrm{Ag}$ and $\mathrm{Ag}_{x} \mathrm{O}$ thin films are depicted.

The XPS spectra of Ag thin film suggested the presence of a doublet with the $\mathrm{Ag} 3 \mathrm{~d} 5 / 2$ peak at $368.6 \mathrm{eV}$, which is reported to correspond to $\mathrm{Ag}-\mathrm{Ag}$ bond, thus suggesting that $\mathrm{Ag}$ coating is in metallic state $[21,22,23]$. No evidence of $\mathrm{Ag}-\mathrm{O}$ bonds is visible which was somehow expectable due to the low reactivity of silver with oxygen. Regarding the $\mathrm{Ag}_{x} \mathrm{O}$ thin film the $\mathrm{Ag} 3 \mathrm{~d}$ spectra clearly revealed the presence of three distinct bonds: $\mathrm{Ag}-\mathrm{Ag}, \mathrm{Ag}$ clusters and $\mathrm{Ag}-\mathrm{O}$, being the third one located at $367.7 \mathrm{eV}$ [24]. The XPS spectra of $\operatorname{Ag}_{x} \mathrm{O}$ clearly show that $\mathrm{Ag}$ is the main phase and only a small contribution of both $\mathrm{Ag}$ clusters and $\mathrm{Ag}-\mathrm{O}$ bonds are visible. The presence of $\mathrm{Ag}-\mathrm{O}$ bond was also visible in the $\mathrm{O} 1 \mathrm{~s}$ spectra, with a peak at 531.0 (see inset in Fig. 2), which revealed the presence of $\mathrm{Ag}-\mathrm{O}[25]$ bond and $\mathrm{C}-\mathrm{O}$ bond, which is found at higher binding energies, being the later associated with surface contamination. The surface contamination inevitably occurs when the material surface is exposed to atmospheric conditions, being very easily detected in

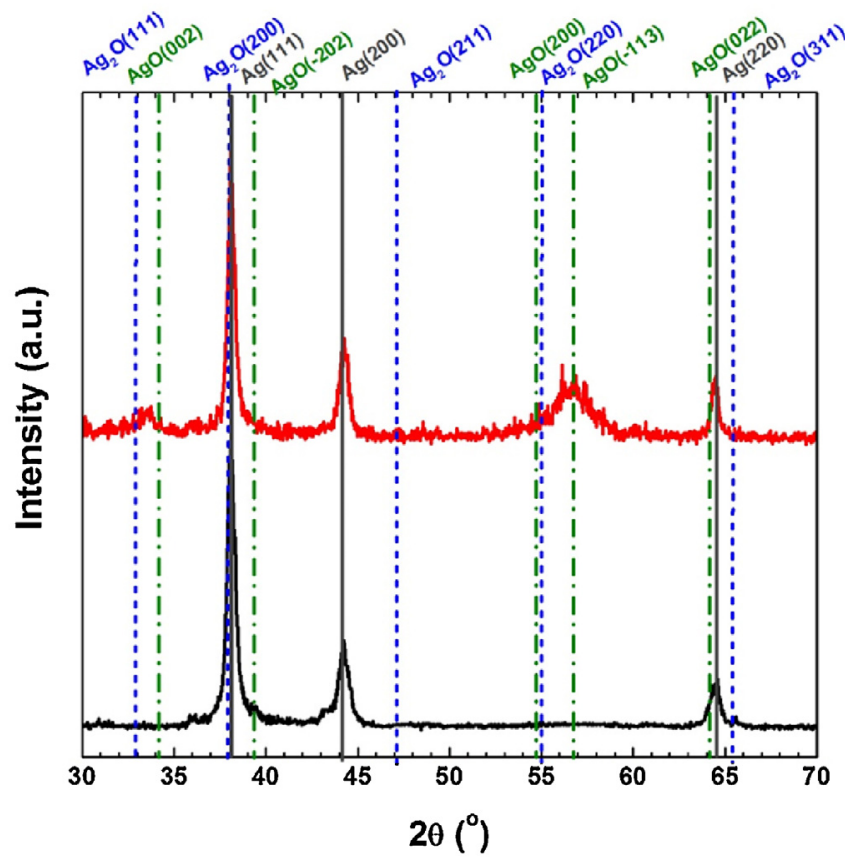

Fig. 3. XRD patterns of $\mathrm{Ag}$ and $\mathrm{Ag}_{x} \mathrm{O}$ coatings.

XPS since the depth of analysis is of few nanometers. In fact, the presence of surface contamination turns the chemical composition analysis inaccurate; still, the results obtained by XPS revealed that the $\mathrm{Ag}_{x} \mathrm{O}$ coating shows an $\mathrm{Ag} / \mathrm{O}$ atomic ratio of 2.3 , a value that is overestimated, since the detected oxygen is a sum of the oxygen present in the coating combined with the oxygen coming from surface contamination.

XRD analysis was performed in order to obtain further information about the coatings structure. The XRD diffraction patterns of $\mathrm{Ag}$ and $\mathrm{Ag}_{x} \mathrm{O}$ coatings are presented in Fig. 3, where the main identified crystalline phases are depicted, namely Ag (ICDD card no. 00-004-0783), AgO (ICDD card no. 00-043-1038) and $\mathrm{Ag}_{2} \mathrm{O}$ (ICDD 00-065-6811).

The XRD pattern of Ag coating reveals that the coating crystallizes in a fcc-Ag crystal structure, being the grain size about $40 \mathrm{~nm}$, for (1 111 ) peak, according to the calculation obtained by the Scherrer method. Regarding the $\mathrm{Ag}_{x} \mathrm{O}$ thin film the presence of crystalline $\mathrm{Ag}$ phase is evident, however a second phase can also be detected, which can correspond to $\mathrm{AgO}$ or $\mathrm{Ag}_{2} \mathrm{O}$. The results obtained in XRD analysis are in good agreement with the XPS analysis, being clear in both techniques that the $\mathrm{Ag}_{x} \mathrm{O}$ coating contains a phase mixture of $\mathrm{Ag}+\mathrm{Ag}_{2} \mathrm{O}$ or $\mathrm{Ag}+\mathrm{AgO}$. Moreover, the $\mathrm{Ag} / \mathrm{O}$ atomic ratio obtained by XPS was above 2 , which means that the amount of oxygen incorporated in the coating is not enough to obtain single phased $\mathrm{Ag}_{2} \mathrm{O}$ or $\mathrm{AgO}$ thin films. Pierson and Rousselot [26] have previously reported the formation of $\mathrm{Ag}$ and $\mathrm{Ag}_{2} \mathrm{O}$ phases during reactive sputtering of silver in oxygen atmosphere. However, the presence of bi-phase coatings was only observed for low oxygen flows, being found that at higher oxygen flows the coatings are composed of a silver oxide single phase, being the $\mathrm{Ag}_{2} \mathrm{O}$ the most common one due to the lower Gibbs free energy associated with its formation. In the present 

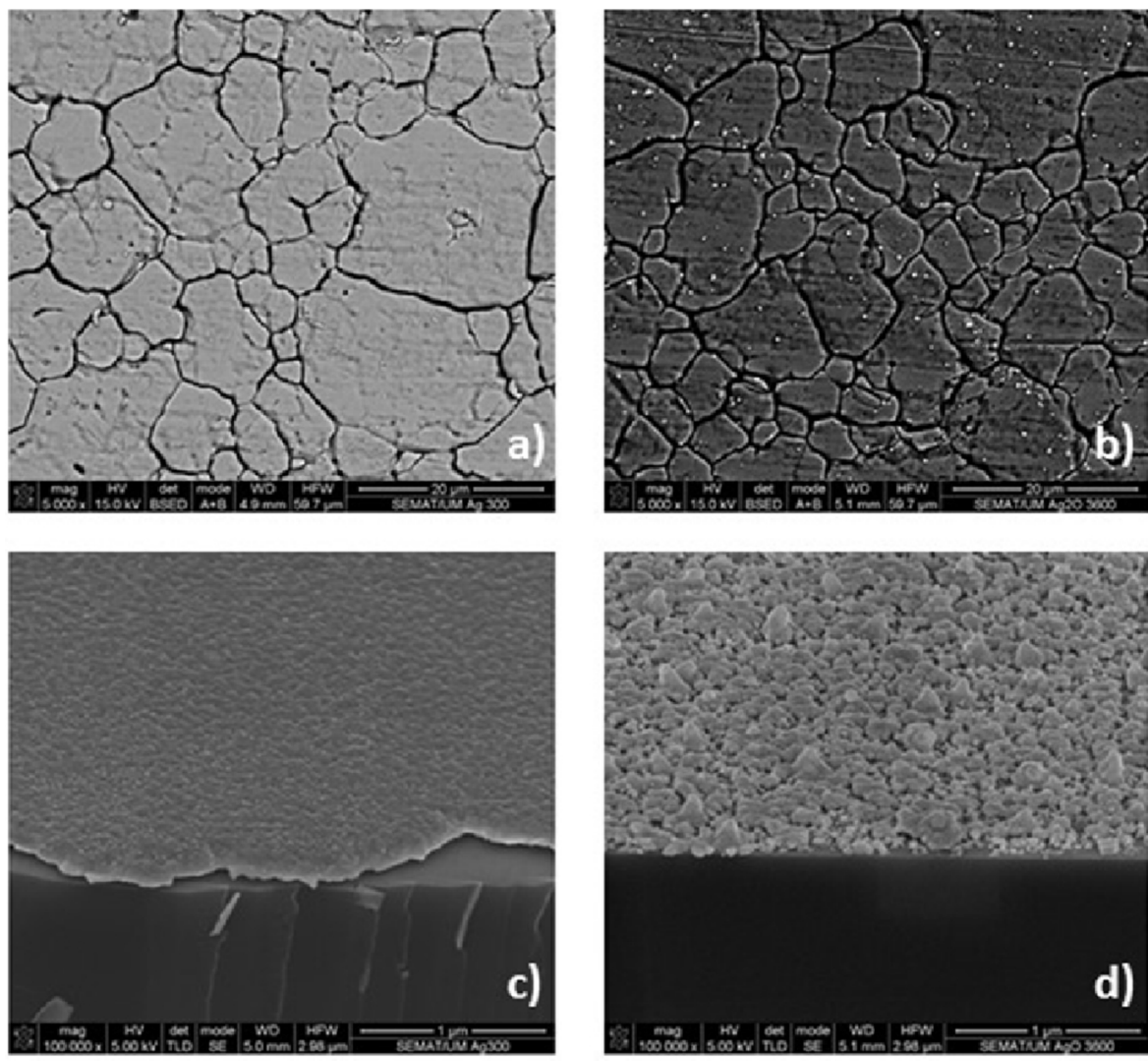

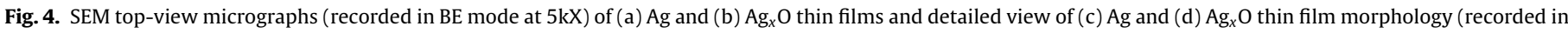
$\mathrm{SE}$ mode at $100 \mathrm{kX})$.

Table 3

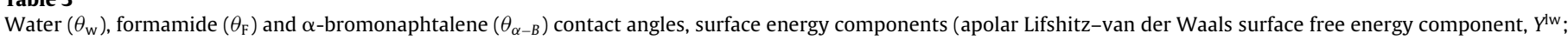

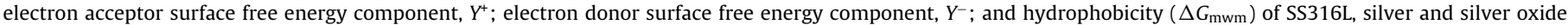
coatings.

\begin{tabular}{|c|c|c|c|c|c|c|c|}
\hline \multirow[t]{2}{*}{ Sample } & \multicolumn{3}{|c|}{ Contact angle \pm S.D. $\left({ }^{\circ}\right)$} & \multicolumn{2}{|c|}{ Surface energy components $\left(\mathrm{mJ} / \mathrm{m}^{2}\right)$} & \multirow[b]{2}{*}{$Y^{-}$} & \multirow[t]{2}{*}{$\Delta G_{\mathrm{mwm}}\left(\mathrm{mJ} / \mathrm{m}^{2}\right)$} \\
\hline & $\theta_{\mathrm{w}}$ & $\theta_{\mathrm{F}}$ & $\theta_{\alpha-B}$ & $Y^{\mathrm{lw}}$ & $Y^{+}$ & & \\
\hline $\mathrm{Ag}$ & $103 \pm 2$ & $86 \pm 8$ & $43 \pm 3$ & 33 & 0 & 2 & -2 \\
\hline $\mathrm{Ag}_{x} \mathrm{O}$ & $103 \pm 3$ & $89 \pm 6$ & $48 \pm 1$ & 31 & 0 & 3 & -2 \\
\hline
\end{tabular}

report the bi-phase coatings were obtained even in deposition in reactive mode, with high oxygen flows.

The coatings morphology was evaluated through SEM analysis. The SEM top-view micrographs (recorded in backscattered electron mode) of $\mathrm{Ag}$ and $\mathrm{Ag}_{x} \mathrm{O}$ coatings are presented in Fig. 4(a) and (b), respectively. A more detailed view of $\mathrm{Ag}$ and $\mathrm{Ag}_{\mathrm{x}} \mathrm{O}$ thin films is shown in Fig. 4(c) and (d), respectively.

The SEM micrographs of both $\mathrm{Ag}$ and $\mathrm{Ag}_{x} \mathrm{O}$ thin films recorded at low magnification suggest the presence of compact coatings surrounded by well-defined interface regions, which correspond to the intergranular regions of SS316L substrate. The SEM micrograph of $\mathrm{Ag}_{x} \mathrm{O}$ thin film (see Fig. 4(b)) suggests the presence of some circular features which appear brighter in the BSE micrograph, thus suggesting some mass contrast in relation to the matrix coating. These features might correspond to Ag agglomerates (showing sizes of several hundred $\mathrm{nm}$ ) which should appear brighter in the BSE images, due to their higher mass in relation to the silver oxide phase, a result which is well correlated with the trends observed in XPS and XRD analysis which also suggests that $\mathrm{Ag}_{x} \mathrm{O}$ coatings are composed of two distinct phases: $\mathrm{Ag}+$ silver oxide. $\mathrm{A}$ more detailed view of $\mathrm{Ag}_{x} \mathrm{O}$ thin film (see Fig. 4(d)) indicates that the thin film is not continuous being composed by islands with hundreds of nanometers in size, surrounded by smaller islands with tens of nanometers. The thickness and deposition rate of $\mathrm{Ag}_{x} \mathrm{O}$ thin film reported in Table 2 refer to the smaller islands. Conversely, the Ag thin film forms a continuous coating (see Fig. 4(c)). Several mechanisms have been pointed out to explain the thin films growth from vapor phase, namely: (1) island (or Volmer-Weber), (2) layer (or Frank-Van der Merwe), and (3) Stranski-Krastanov, being the occurrence of each mechanism dependent on the interaction between the adatoms and the substrate. The occurrence of island growth mechanism observed in $\mathrm{Ag}_{x} \mathrm{O}$ thin film occurs when the atoms or molecules in the deposit are more strongly bounded to each other than to the substrate, which promotes the clustering of metal atoms. As the amount of deposited metal is increased the number of stable nuclei will grow up to a maximum and aftermost diminish due to coalescence phenomena, which eventually will lead to the formation of a continuous coating as observed in Ag thin film (see Fig. 4(c)). Another interesting feature observed in $\mathrm{Ag}_{x} \mathrm{O}$ thin film is the bimodal size distribution, being clearly found that the surface is covered by bigger islands with hundreds of nanometers surrounded by smaller islands with tens of nanometers. This bimodal size distribution suggests the presence of two different phases with different coalescence and growth rates. The 

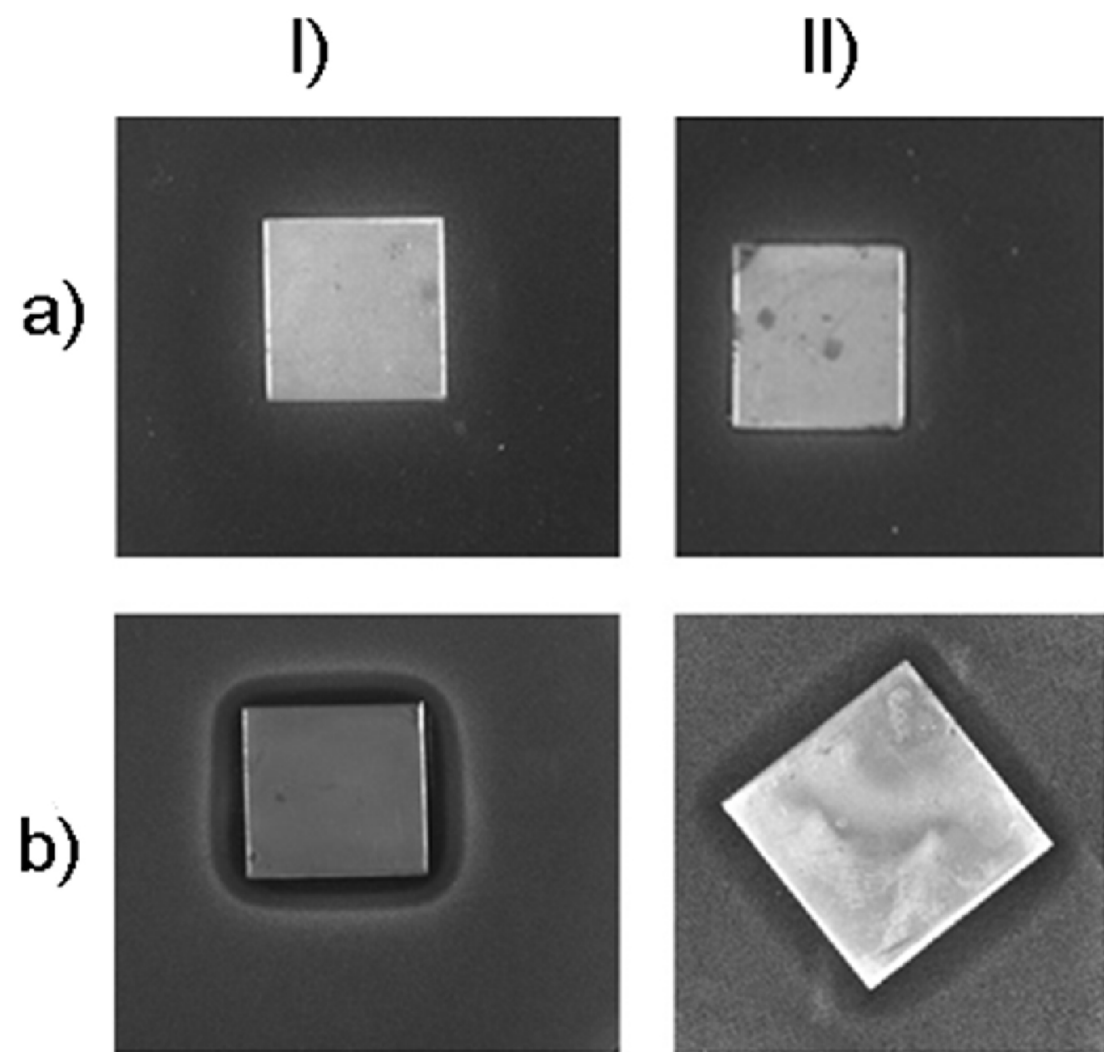

Fig. 5. Results of antibacterial tests for $\mathrm{Ag}(\mathrm{a})$ and $\mathrm{Ag}_{x} \mathrm{O}$ (b) regarding Staphylococcus epidermidis (I) and Staphylococcus aureus (II).

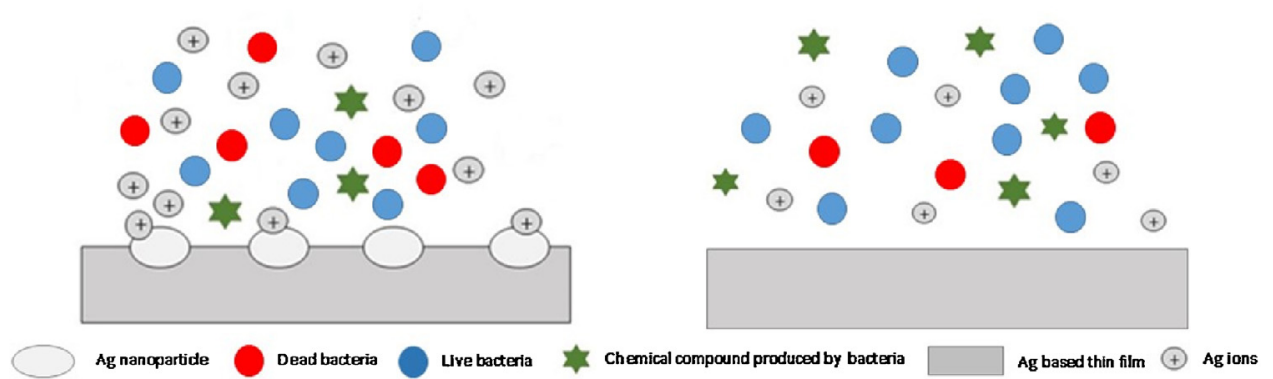

Fig. 6. Schematic illustrations of possible mechanisms of Ag dissolution, with and without Ag nanoparticles, when in contact with bacteria (adapted from [34]).

bigger Ag islands with hundreds of nanometers should correspond to $\mathrm{Ag}$, considering the results shown in Fig. 4(b), still it is difficult to unequivocally identify to which phases the bigger and smaller islands correspond.

\subsection{Surface properties}

The surface characteristics such as interaction with water and surface free energy play a major role in biomedical devices, since numerous physiological events are determined by these surface properties. According to the van Oss approach the hydrophobicity of a material is defined by the variation of the free energy of interaction $(\Delta G)$ between the material's surface $(\Delta m)$ immersed in water $(w), \Delta G_{\mathrm{mwm}}$. When this variation is negative, there is a greater interaction between material's molecules than with water, which leads to a hydrophobic surface. On the other hand when $\Delta G_{\mathrm{mwm}}$ is positive the material's surface is hydrophilic [5]. In addition the water contact angle also allows the evaluation of the surface hydrophobic or hydrophilic character, since higher contact angles (above $90^{\circ}$ or $65^{\circ}$ defended for some authors [27]) reveal the presence of hydrophobic surfaces, while lower water contact angles imply a more hydrophilic surface [5].

The hydrophobicity of a surface plays an important role in microorganism's adhesion since a higher density of apolar areas in material's surface promote an attachment of microorganism via the hydrophobic effect, due to the increment of hydrophobic interactions [28].

The contact angles, surface energy parameters and the degree of hydrophobicity of $\mathrm{Ag}$ and $\mathrm{Ag}_{x} \mathrm{O}$ thin films are presented in Table 3.

The water contact angles obtained for $\mathrm{Ag}$ and $\mathrm{Ag}_{x} \mathrm{O}$ samples revealed a value higher than $90^{\circ}$, thus indicating that all surfaces are hydrophobic, which is also confirmed by the negative $\Delta G_{\mathrm{mwm}}$ 
values [5]. Moreover, the $\theta_{\mathrm{w}}$ values are statistically similar ( $t$-test, $p>0.05)$ for all surfaces and no great variations in $\Delta G_{\mathrm{mwm}}$ are observed, thus suggesting a very similar hydrophobic character for all surfaces. Additionally, coatings present a monopolar surface $\left(Y^{+}=0\right.$ and $Y^{-}=2.34$ and $Y^{-}=2.72$ for $\mathrm{Ag}$ and $\operatorname{Ag}_{x} \mathrm{O}$, respectively).

\subsection{Antibacterial activity}

Halo inhibition zone tests were performed in order to assess the coatings antibacterial efficiency against $S$. epidermidis and $S$. aureus. The results obtained for both tested coatings against these two types of bacteria are presented in Fig. 5.

Concerning the antibacterial tests, the results were similar for both bacteria. In Fig. 5(a) it is possible to observe that the bacteria grew all around the $\mathrm{Ag}$ coating (no inhibition halo formation was observed). Nonetheless, coating $\mathrm{Ag}_{x} \mathrm{O}$ (Fig. 5(b)) presented halo around the sample, which means that there is an inhibition zone of bacteria growth. However, for S. epidermidis (Fig. 5(b)(I)) the halo presented for these samples is completely clear in the zone nearby the sample and became less clear when it moves away, which suggest that there is a zone of non-growth of bacteria (clear halo) and a zone of inhibition of bacteria growth (diffuse halo), which may be due to the silver release to the agar medium. For S. aureus there is not visible a clear halo, which indicates that there is a zone of inhibition of bacteria growth but there is not a complete death of bacteria. Similar results, where S. epidermidis presented more sensitive to silver than $S$. aureus has been previously reported [29].

The contact angle measurements suggested that $\mathrm{Ag}$ and $\mathrm{Ag}_{x} \mathrm{O}$ coated SS316L present very similar surface characteristics (surface energy parameters and the degree of hydrophobicity), in this sense, the differences in biological properties cannot be attributed to any changes in surface properties. Thus, the different behaviors can only be attributed to the $\mathrm{Ag}$ antibacterial activity, which seems to be different in $\mathrm{Ag}$ and $\mathrm{Ag}_{x} \mathrm{O}$ thin films. Recently, proteomic analysis revealed that even a short exposure of silver nanoparticles to bacterium cells resulted in alterations in the expression of a panel of envelope and heat shock proteins. Ag nanoparticles can penetrate and disrupt the membranes of bacteria, providing a loss of intracellular potassium. Furthermore, Ag nanoparticles decreased the ATP levels, which culminates with the death of bacteria [30,31]. Similar results can be observed with silver ions. Although pure metallic silver is stable in usual conditions and, consequently, has low solubility in water [12], when in contact with bacteria, some chemical compounds, that facilitate the release of $\mathrm{Ag}^{+}$ions, are formed and, therefore, increase the antibacterial activity [32]. $\mathrm{Ag}^{+}$ions penetrate the bacteria cell wall and bind to phospholipid layer of the cytoplasmic membrane and to bacteria DNA disrupting its replication [33]. Regarding the antibacterial results, it is clear that there is antibacterial activity only in $\mathrm{Ag}_{x} \mathrm{O}$ sample. So, these results suggest that the form of silver (NP's; clusters; islands or continuous films) could have influence on the antibacterial efficacy; in addition the presence of silver oxide matrix could promote the release of silver. In Fig. 6 a possible mechanisms of Ag dissolution when in contact with bacteria is represented, for both studied coatings: $\mathrm{Ag}_{x} \mathrm{O}$ (which surface is composed of islands combined with smaller $\mathrm{Ag}$ nanoparticles) and $\mathrm{Ag}$ (which form a continuous thin film).

Althgouth the mechanism of silver release from metallic surfaces is poorly understood [35], the silver form plays an extremely important role in antimicrobial behavior of silver based surfaces. In fact, the Ag thin film which formed a continuous layer based on crystalline $\mathrm{Ag}$ phase did not show any evidence of antibacterial activity, conversely the $\operatorname{Ag}_{x} \mathrm{O}$ thin film which is composed of islands and small Ag nanoparticles, being mainly composed by a mixture of $\mathrm{Ag}$ and silver oxide crystalline phases, showed indication of antibacterial activity. As previously mentioned,the activity of nanosilver is predominantly associated with the presence of $\mathrm{Ag}^{+}$ ions and also to small $\mathrm{Ag}$ nanoparticles, which tend to be more easily ionized [36], being also claimed that they are able to directly interact with bacteria promoting their destruction. The presence of silver clusters and silver agglomerates in $\mathrm{Ag}_{x} \mathrm{O}$ sample (see Fig. 4(d)) results in a higher exposed surface area when compared with continuous $\mathrm{Ag}$ layer, consequently, a higher release of $\mathrm{Ag}^{+}$ions could be expected when the surface is exposed to the TSA and bateria medium.

\section{Conclusions}

Silver and silver oxide thin films were deposited by non-reactive (for $\mathrm{Ag}$ thin film) and reactive (for $\mathrm{Ag}_{x} \mathrm{O}$ thin film) pulsed $\mathrm{DC}$ magnetron sputtering in order to assess the coatings antibacterial activity against $S$. epidermidis and $S$. aureus, two of the most common bacteria associated with nosocomial infections found in cardiovascular stents. The structural and morphological characterizations revealed that $\mathrm{Ag}$ thin film forms a continuous layer, with a thickness of $66 \mathrm{~nm}$, composed by crystalline fcc-Ag phase. The incorporation of oxygen in the deposition atmosphere lead to the formation of a thin film composed by a mixture of two crystalline phases: Ag and silver oxide. The latter thin film was characterized by the presence of islands with several hundreds of nanometers surrounded by smaller nanoparticles with tens of nanometers.

The halo inhibition zone tests revealed the antibacterial behavior of $\mathrm{Ag}_{x} \mathrm{O}$ thin films against both of the tested bacteria; conversely no antibacterial effect was found in Ag thin film. The differences between these two coatings might be related not only to the presence of silver oxide phase, but also to the differences found in coatings growth mode; with Ag coatings forming a continuous layer and $\mathrm{Ag}_{x} \mathrm{O}$ forming islands surrounded by smaller nanoparticles. These differences might lead to better interaction between the thin film surface and bacteria, due to the higher surface to volume ratio, which can increase the $\mathrm{Ag}$ ionization rate or the direct interaction between $\mathrm{Ag}$ and bacteria. The obtained results suggest that $\mathrm{Ag}_{x} \mathrm{O}$ coating, deposited by reactive $\mathrm{DC}$ magnetron sputtering, present antimicrobial properties for both bacteria used and it has great potencial to be applied in cardiovascular stents.

\section{Acknowledgments}

The authors acknowledgments the financial support of FCT-Fundação para a Ciência e Tecnologia through grants: SFRH/BD/90321/2012 and SFRH/BD/82472/2011.

Also thank support by FEDER through the COMPETE Program and by the Portuguese Foundation for Science and Technology (FCT) in the framework of the Strategic Project PESTC/FIS/UI607/2014, and projects ERA-SIINN/0004/2013 and the project Matepro-Optimizing Materials and Processes, ref. NORTE07-0124-FEDER-000037", co-funded by the "Programa Operacional Regional do Norte" (ON.2-O Novo Norte), under the "Quadro de Referência Estratégico Nacional" (QREN), through the "Fundo Europeu de Desenvolvimento Regional" (FEDER).

\section{References}

[1] M. Nichols, N. Townsend, R. Luengo-Fernandez, J. Leal, A. Gray, P. Scarborough, M. Rayner, European Cardiovascular Disease Statistics 2012, European Heart Network, European Society of Cardiology, 2012.

[2] N. Vila, Braided Hybrid Stents Design, in Master Thesis on Design and Marketing, University of Minho, 2009.

[3] L. França, A. Pereira, Update on vascular endoprostheses (stents): from experimental to clinical pratice, J. Vasc. Bras. 7 (2008).

[4] L. Rodrigues, Inhibition of bacterial adhesion on medical devices, Adv. Exp. Med. Biol. 715 (2011) 351-367.

[5] I. Carvalho, M. Henriques, J. Oliveira, C. Alves, A. Piedade, S. Carvalho, Influence of surface features on the adhesion of Staphylococus epidermidis to Ag-TiCN thin films, Sci. Technol. Adv. Mater. 14 (3) (2013) 1-10. 
[6] W. Bosman, B. Borger van der Burg, H. Schuttevaer, S. Thoma, P. Hedeman Joosten, Infections of intravascular bare metal stents: a case report and review, Eur. J. Vasc. Endovasc. Surg. 47 (1) (2014) 87-99.

[7] S.P. Hawser, S.K. Bouchillon, D.J. Hoban, M. Dowzicky, T. Babinchak, Rising incidence of Staphylococcus aureus with reduced susceptibility to vancomycin and susceptibility to antibiotics: a global analysis 2004-2009, Int. J. Antimicrob. Agents 37 (2011) 219-224.

[8] O. Lyutakov, I. Goncharova, S. Rimpelova, K. Kolarova, J. Svanda, V. Svorcik, Silver release and antimicrobial properties of PMMA films doped with silver ions, nano-particles and complexes, Mater. Sci. Eng. C 49 (2015) 534-540.

[9] M.L.W. Knetsch, L.H. Koole, NEw strategies in the development of antimicrobial coatings: the example of increasing usage of silver and silver nanoparticles, Polymers 3 (2011) 340-366.

[10] P. Dallas, V.K. Sharma, R. Zboril, Silver polymeric nanocomposites as advanced antimicrobial agents: classification, synthetic paths, applications, and perspectives, Adv. Colloid Interface Sci. 166 (2011) 119-135.

[11] N. Vu, A. Zille, F. Oliveira, N. Carneiro, A. Souto, Effect of particle size on silver nanoparticle deposition onto Dielectric Barrier Discharge (DBD) plasma functionalized polyamide fabric, Polymers 10 (2013).

[12] S. Sant, K. Gill, R. Burrell, Nanostructure, dissolution and morphology characteristics of microcidal silver films deposited by magnetron sputtering, Acta Biomater. 3 (2006) 341-350.

[13] R. Rebelo, R. Fangueiro, S. Carvalho, M. Henriques, S. Rana, Methods of incorporation antimicrobial agents in stents, Int. J. Eng. Sci. Innovative Technol. (IJESIT) 3 (2) (2014) 409-422.

[14] S. Spadaro, S. Chase, D. Webster, Bacterial inhibition by electrical activation of percutaneous silver implants, J. Biomed. Mater. Res. (1986) 565-577.

[15] S.B. Sant, K. Gill, R. Burrell, The nature of chemical species in novel antimicrobial silver films deposited by magnetron sputtering, Philos. Mag. A 82 (6) (2002).

[16] M. Anzano, A. Tosti, M. Lasagni, A. Campiglio, D. Pitea, E. Collina, Antimicrobial activity of thin metallic silver flakes, waste products of a manufacturing process, J. Environ. Sci. 23 (9) (2011) 1570-1577.

[17] C. Lok, C. Ho, R. Chen, Q. He, W. Yu, H. Sun, P. Tam, J. Chiu, C. Che, Silver nanoparticles: partial oxidation and antibacterial activities, J. Biol. Inorg. Chem. 12 (2007) 527-534.

[18] D. Carter, H. Walde, G. McDonough, G. Roche, Parameter optimization in pulsed Dc reactive sputter deposition of aluminum oxide, 45th Annual Technical Conference Proceedings (2002).

[19] D. Depla, J. Haemers, R. De Gryse, Discharge voltage measurements during reactive sputtering of oxides, Thin Solid Films 515 (2006) 468-471.

[20] J. Pierson, D. Wiederkerkehr, A. Billard, Reactive magnetron sputtering of copper, silver and gold, Thin Solid Films 478 (2005) 196-205.

[21] F. Paladini, R. Picca, M. Sportelli, N. Cioffi, A. Sannino, M. Pollini, Surface chemical and biological characterization of flax fabrics modified with silver nanoparticles for biomedical applications, Mater. Sci. Eng. C 52 (2015) 1-10.
[22] S. Calderon, R. Escobar Galindo, N. Benito, C. Palacio, A. Cavaleiro, S. Carvalho, $\mathrm{Ag}^{+}$release inhibition from $\mathrm{ZrCN}-\mathrm{Ag}$ coatings by surface agglomeration mechanism: structural characterization, J. Phys. D: Appl. Phys. 46 (2013).

[23] A. Ferraria, A. Carapeto, A. Rego, X-ray photoelectron spectroscopy: silver salts revisited, Vaccum 86 (2012) 1988-1991.

[24] C. Vicent, Handbook of Monochromatic XPS Spectra, The Elements of Native Oxides, Wiley, 2000.

[25] V. Kaushik, XPS core level spectra and auger parameters for some silver compounds, J. Electron Spectrosc. Relat. Phenom. 56 (3) (1991) 273-277.

[26] J. Pierson, C. Rousselot, Stability of reactively sputtered silver oxide films, Surf. Coat. Technol. 200 (2005) 276-279.

[27] E.A. Vogler, Protein adsorption in three dimensions, Biomaterials 33 (2012) 1201-1237

[28] I. Carvalho, M. Henriques, S. Carvalho, New strategies to fight bacterial adhesion, in: Microbial Pathogens and Strategies for Combating Them: Science, Technology and Education, Formatex Research Center, 2013, pp. $170-178$.

[29] R. Bayston, L. Vera, A. Mills, W. Ashraf, O. Stevenson, S.M. Howdle, In vitro antimicrobial activity of silver-processed catheters for neurosurgery, J. Antimicrob. Chemother. 65 (2010) 258-265.

[30] N. Durán, P. Marcato, R. De Conti, O. Alves, F. Costa, M. Brocchi, Potential use of silver nanoparticles on pathogenic bacteria, their toxicity and possible mechanisms of action, J. Braz. Chem. Soc. 21 (6) (2010) 949-959.

[31] A. Ivanovaa, R. Surmeneva, M. Surmeneva, T. Mukhametkaliyev, K. Lozab, O. Prymakb, M. Epple, Hybrid biocomposite with a tunable antibacterial activity andbioactivity based on RF magnetron sputter deposited coating andsilver nanoparticles, Appl. Surf. Sci. 329 (2015) 212-218.

[32] I. Incerti, A. Rota, S. Valeri, A. Miguel, J. García, R. Rodríguez, J. Osés, Nanostructured self-lubricating $\mathrm{CrN}-\mathrm{Ag}$ films deposited by PVD arc discharge and magnetron sputtering, Vacuum 85 (2011) 1108-1113.

[33] J. Ricco, O. Assadian, Antimicrobial silver grafts for prevention and treatment of vascular graft infection, Semin. Vasc. Surg. 4 (2011) 234-241.

[34] W. Chiang, I. Tseng, P. Moller, L. Hilbert, T. Nielsen, J. Wu, Influence of silver additions to type 316 stainless steels on bacterial inhibition, mechanical properties, and corrosion resistance, Mater. Chem. Phys. 119 (2010) 123-130.

[35] S. Ferrarisa, S. Perero, M. Miola, E. Vernè, A. Rosiello, V. Ferrazzo, G. Vallettab, J. Sanchez, M. Ohrlander, S. Tjörnhammar, M. Fokine, F. Laurell, E. Blomberg, S. Skoglund, I. Odnevall Wallindere, M. Ferraris, Chemical, mechanical and antibacterial properties of silvernanocluster/silica composite coated textiles for safety systems and aerospace applications, Appl. Surf. Sci. 317 (2014) $131-139$.

[36] J. Hu, C. Muratore, A. Voevodin, Silver diffusion and high-temperature lubrication mechanisms, Compos. Sci. Technol. 67 (2007) 336-347. 